\title{
CONTRIBUTION TO THE PARAMETRIC STUDY OF THE PERFORMANCE OF A PARABOLIC TROUGH COLLECTOR
}

\author{
Belkacem Bouali $^{1^{*}}$ and Hanane-Maria Regue ${ }^{2}$ \\ ${ }^{1}$ Laghouat University, Process Engineering Laboratory, Laghouat -03000, Algeria \\ ${ }^{1}$ Laghouat University, Mechanical Engineering Laboratory, Laghouat -03000, Algeria
}

\begin{abstract}
This paper presents an analysis of the performance of a parabolic trough collector (PTC) according to some key operating parameters. The effects of the secondary reflector, the length and thickness of the absorber tube (receiver tube) and the flow rate of the heat transfer fluid (HTF) are investigated. The main objective is to determine an optimal operation, which improves the performance of a traditional PTC. The target variables are the temperature at the outlet of the tube, the amount of energy collected by the HTF and the efficiency of the system. The solar flux data concern the city of LAGHOUAT located in the south of Algeria. Four days in different seasons are considered. The optical analysis of the system is performed by using the open source SolTrace code. The output of this analysis is used as a boundary condition for the CFD solver. The conjugate heat transfer and the fluid flow through the absorber tube are simulated by using ANSYS-CFX solver. Water is considered as heat transfer fluids. The obtained results show that the use of a curved secondary reflector significantly improves the performance of the traditional PTC. As the thickness of the tube increases, the heat storage in the material increases, which increases the temperature at the exit of the tube and therefore the efficiency of the system. However, the length of the tube depends on the mass flow of the HTF and vice versa. To keep the efficiency constant by choosing another length, it is necessary to choose a mass flow rate proportional to the flow rate corresponding to the initial length.
\end{abstract}

\section{Introduction}

Solar energy is the main renewable energy source that can contribute significantly to a growing energy demand. It is highly reliable and allows more energy generation rate than other renewable resources. In addition, it is not only related to its economic benefits but, in particular, to protect the environment where we must find solutions to the problems of pollution (Clean energy). In nature, there are several sources of renewable energy including solar. Solar thermal is now technically reliable and many achievements exist (solar water heaters, solar homes, solar collectors...) [1].

Concentrated solar power (CSP) is one of the proven methods of energy conversion. In this technique, solar collectors, which are special heat exchangers, are used. A solar thermal collector is a device, which collects the sun's rays and focuses on to the receiver tube. The receiver tube absorbs the thermal energy from the radiation and transfers the energy to the heat transfer fluid (HTF) circulating through the receiver tube. Habitually, the fluid used is thermal oil, air or water according to the nature of application. Four different kinds of CSP power generation plants are found; those are 1) solar parabolic dishes (SPD), 2) parabolic trough collectors (PTC), 3) solar power tower (SPT), and 4) linear Fresnel reflectors (LFR) [2]. The technology of PTC is one of the most appropriate technologies for the solar energy exploitation and it is one of the proven and of the low cost large-scale solar power technologies available [2,3].

In recent years, many researchers have focused on designing and improving various small-scale PTCs for low and medium heat production purposes. The main objective is to improve the performances of the absorber and to find the measures to achieve the best price saving ratio relative to fossil fuels. Roy et al. [4] presented a parametric experimental study of a parabolic trough collector. The effects of water inlet temperature and mass flow rate are investigated. The study showed that there are optimal values for these two parameters. The highest thermal efficiency obtained is about $65 \%$ when the optimum values are used simultaneously. Ghomrassi et al [5] analyzed the effect of the receiver tube diameter variations on the PTC performance. They used a collector tube covered with a metallic thickness and compared its performance to those of the same diameter without the addition of metallic thickness. The CFD simulation results of this procedure showed that increasing the metallic thickness improves the PTC thermal performance. Marif et al [6] developed a computer program in order to determine the optical and thermal performance of a PTC with liquid water and Therminol VP-1TM synthetic oil as HTF under the climate conditions of Algerian Sahara. The simulation results showed principally that the one axis polar East-West and horizontal East-West tracking systems were most desirable for a parabolic trough collector throughout the

\footnotetext{
* Corresponding author: bouali-b@hotmail.com
} 
whole year. In order to enhance the heat transfer in the PTC collector tube, Kumar et al. [7] proposed to insert a porous disc at inner surface of the receiver tube. They showed that this technique significantly improves the PTC performance. Another similar idea has been proposed by Mwesigye et al. [8]. They showed that the use of perforated plate inserts increases the thermal efficiency of the receiver in the range $1.2 \%$ and $8 \%$ depending on the insert spacing, insert size and Reynolds number. Certain optical parameters influencing the performance of a PTC have attracted the attention of researchers. For example, He et al. [9] used the MCRT code and Fluent software to discuss the effects of geometric concentration ratio and rim angle on the collector tube heat transfer and fluid flow performance. The results show that the two variables affect significantly the heat flux distribution on the absorber tube. On the other hand, the HTF has also caught the attention of researchers. Kaloudis et al. [10] investigated numerically, by using ANSYS- CFX solver [11], a Parabolic Trough Collector system with Syltherm 800/A12O3 nanofluid as the Heat Transfer Fluid. This study showed that a $10 \%$ increase in the efficiency of the collector is possible for an $\mathrm{Al} 2 \mathrm{O} 3$ concentration of $4 \%$. Several other studies have focused on the conjugate heat transfer and HTF flow within the absorber tube [12-15]. The main objective is to obtain a uniform distribution of the heat flow around the tube and to improve the heat transfer to the HTF. In the same context, some authors, (see for example [16-18]) have proposed the use of a twostage reflection. The second stage reflector helps to increase the concentration ratio without increasing the primary mirror size. Therefore, the majority of solar rays lost after the first reflection can be recovered. The result is to obtain maximum heat flow around the absorber tube with a uniform distribution.

As can be seen from the previous review, studies are always focused on improving the performance of the PTC system. The parameters analysed are optical, thermal or geometric. However, we did not find, in the available literature, any optimization studies, which bring together these three categories of parameters. This paper presents a parametric analysis of the performance of a parabolic trough collector according to the simultaneous effects of the mentioned parameters among others: the secondary reflector, the length and thickness of the absorber tube (receiver tube) and the HTF mass flow rate.

\section{METHODOLOGY}

Figure 1 shows the diagram of a conventional PTC. The study of the performance of this system goes through four stages:

First, the solar flux data for the region in question must be determined. In our case, PVsys software is used to provide meteorological data concerning Laghouat city located in southern Algeria $\left(2^{\circ} 56\right.$ Longitude, $33^{\circ} 46$ Latitude and $700 \mathrm{~m}$ Altitude).

Then, an optical analysis of the reflector-tube system is performed. To do this, the open source SolTrace code is used in order to determine the distribution of heat flux around the side surface of the collector tube. This transient distribution is interpolated using a Gaussian function, which will be implemented in the CFD solver as a heat flux boundary condition.

The next step is the numerical resolution of the governing equations of the conjugate heat transfer and the HTF flow in the collector tube. ANSYS-CFX CFD solver is used to solve the governing equations.

Finally, the results obtained by the CFD solver (HTF velocity and temperature distribution) are used to calculate the thermal performance of the system (useful thermal energy and thermal efficiency).

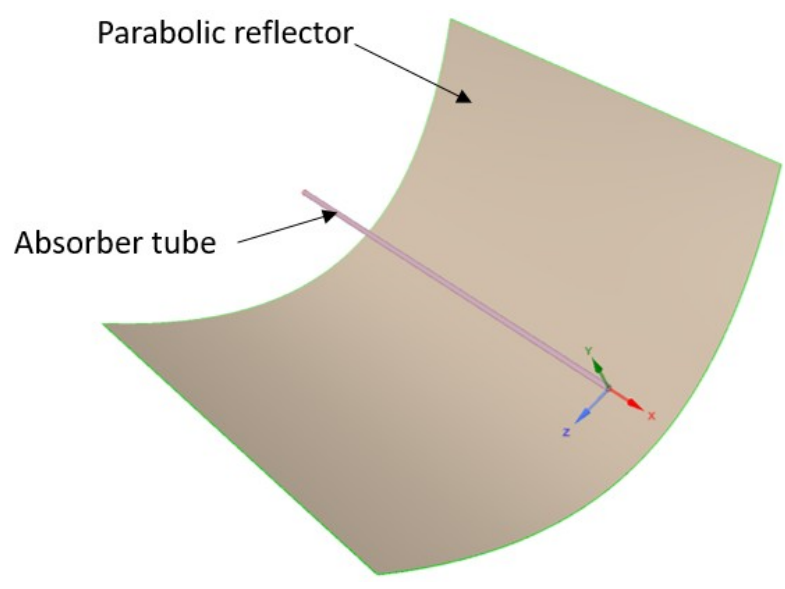

Fig. 1. Schematic of a simple PTC

\section{GOVERNING EQUATIONS}

As it was mentioned in the previous section, the optical study is performed using the SolTrace code, which uses a generalized Monte Carlo method for ray tracing. The main objective of this study is to determine the distribution of the solar flux reflected by the parabolic reflector on the surface of the collector tube. This distribution serves as a heat flux boundary condition for the CFD solver. The conjugate heat transfer and HTF fluid flow within the absorber tube are governed by the following equations [10]:

- Continuity:

$$
\frac{\partial \rho}{\partial t}+\nabla(\rho U)=0
$$

\section{- Momentum}

$$
\frac{\partial(\rho U)}{\partial t}+\nabla \cdot(\rho U \otimes U)=-\nabla p+\mu \nabla . \nabla U
$$

\section{- Thermal energy}

$$
\frac{\partial(\rho h)}{\partial t}+\nabla(\rho U h)=\nabla \cdot(\lambda \nabla T)
$$

Where, $U$ is the velocity vector, $p$ is the fluid pressure, $T$ is the temperature and $h$ is the enthalpy of the HTF.

Note that equation (3) is written for both solid (tube) and fluid (HTF). 
Once the velocity and temperature fields are determined, the system performance is calculated using the following equations:

- Useful heat energy

$$
Q_{u}=\dot{m} C_{p}\left(T_{\text {out }}-T_{\text {in }}\right)
$$

- $\quad$ Thermal efficiency

$$
\eta=\frac{\dot{m} C_{p}\left(T_{\text {out }}-T_{\text {in }}\right)}{A_{C} I_{b}(t)}
$$

Where, $\dot{m}$ is the mass flow rate $(\mathrm{kg} / \mathrm{s}), C_{p}$ is the specific heat capacity $(\mathrm{J} / \mathrm{kg} . \mathrm{K}), I_{b}$ is the direct solar radiation $\left(\mathrm{W} / \mathrm{m}^{2}\right), T_{\text {out }}$ is the outlet temperature of the $\mathrm{HTF}, T_{i n}$ is the inlet temperature of the HTF, and $A_{C}$ is the aperture area of the collector. $A_{C}$ is given as follows:

$$
A_{C}=L . W
$$

Where $W$ and $L$ are respectively the width and the length of the collector tube.

\section{RESULTS AND DISCUSSION}

In this section, we present the key parameters influencing the operation of a PTC. To do this, we first consider an initial configuration of a conventional PTC. As shown in figure 2, the reflector has the dimensions $1 \mathrm{~m} \times 1 \mathrm{~m}$ and the collector tube has an inner diameter of $1 \mathrm{~cm}$ and a thickness of $1 \mathrm{~mm}$. The materials used are aluminium for the reflector and copper for the collector tube, and the heat transfer fluid is water.

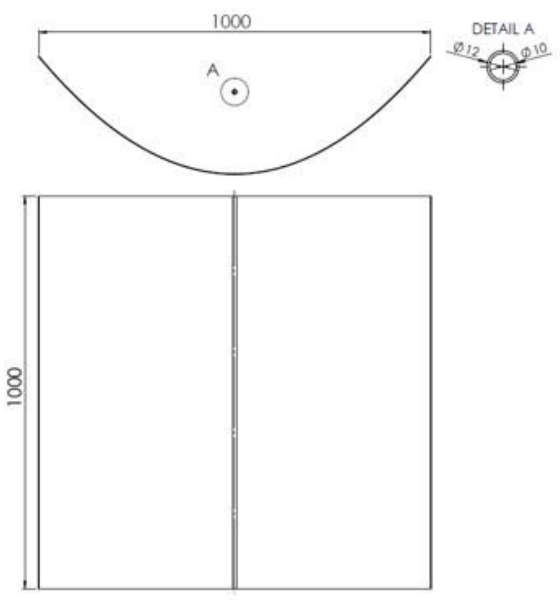

Fig. 2. PTC initial configuration

\subsection{Solar irradiance}

The first step is to determine the solar flux density for the city of Laghouat. PVsyst software is used and the results obtained are shown in Figure 3. Note that two days of two different seasons are represented. In a previous paper [19], we showed that the efficiency of the system remains practically the same during the four seasons. Therefore, in the next investigations only the month of June (where the solar potential is maximum) is considered.

As can be seen, the maximum solar radiation is reached at $1 \mathrm{pm}$ for the two cases shown. In the rest of the time, the distribution is close to a perfect Gaussian.

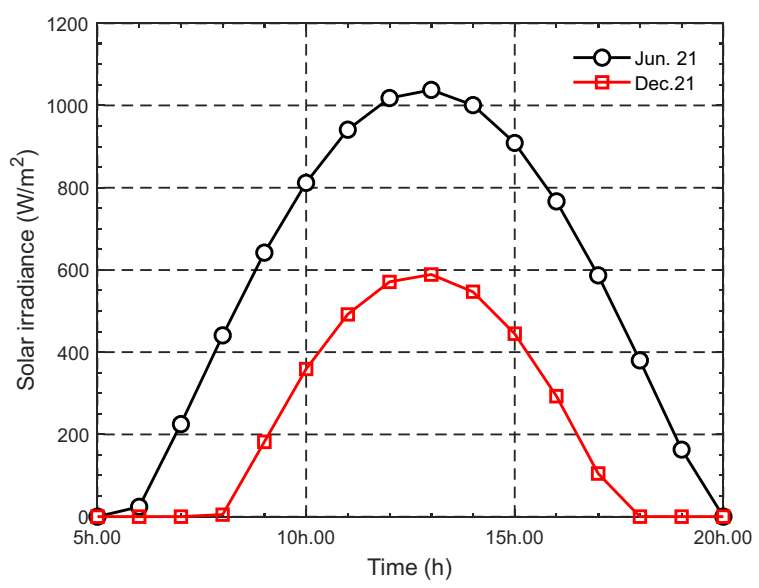

Fig. 3. Solar irradiance for Laghouat city (year 2020)

\subsection{Performance of the initial Configuration}

To determine the performance of the system, the governing equations of the conjugate heat transfer and HTF flow in the absorber tube must be solved. However, the solver needs the transient distribution of the heat flow as a boundary condition on the lateral surface of the tube. This boundary condition represents the output of the optical analysis of the system. This is done using the open source software SolTrace. Values of the heat flux applied to the lateral surface of the tube at each hour are determined. To obtain the values of the heat flux at any time, the hourly values obtained by SolTrace are interpolated by using Gaussian functions. These functions are then implemented in Ansys-CFX Solver using CEL language specific to the software. This procedure is used in all the simulations presented in this work.

The form of these functions is as follows:

$$
q=\sum_{1}^{n=2,3 \ldots} a_{n} \exp \left(\left(t-b_{n}\right) / c_{n}\right)^{2}
$$

Where, $a_{n}$ are heat flux coefficient $\left(\mathrm{W} / \mathrm{m}^{2}\right)$ and $b_{n}, c_{n}$ are time coefficients (hour).

As an example, the values of these coefficients are listed in Table 1 for the initial configuration of the PTC. 
Table 1. Gaussian coefficient of the heat flux distribution for the initial PTC configuration

\begin{tabular}{|l|c|c|c|}
\hline Coeff. & $a n\left(\mathrm{~W} / \mathrm{m}^{2}\right)$ & $b n(\mathrm{~h})$ & $c n(\mathrm{~h})$ \\
\hline Dec. 21 & $a 1=17910$ & $b 1=12.8$ & $c 1=3.363$ \\
\hline \multirow{2}{*}{ Jun. 21} & $a 1=-982300$ & $b 1=13.2$ & $c 1=9.098$ \\
\cline { 2 - 4 } & $a 2=1012000$ & $b 2=13.18$ & $c 2=8.892$ \\
\hline
\end{tabular}

The thermal performance to be determined are the HTF temperature at the tube outlet, the heat gained by the HTF and the system efficiency. These characteristics are represented respectively in Figure 4 (a), (b) and (c).

The maximum of the HTF temperature at the outlet of the tube (about $68^{\circ} \mathrm{C}$ ) and the energy absorbed by the latter (about $315 \mathrm{~W}$ ) are reached at 1 p.m. However, the efficiency of the system is constant for the month of June and is about $29 \%$, and the efficiency for the month of December fluctuates around $29 \%$.

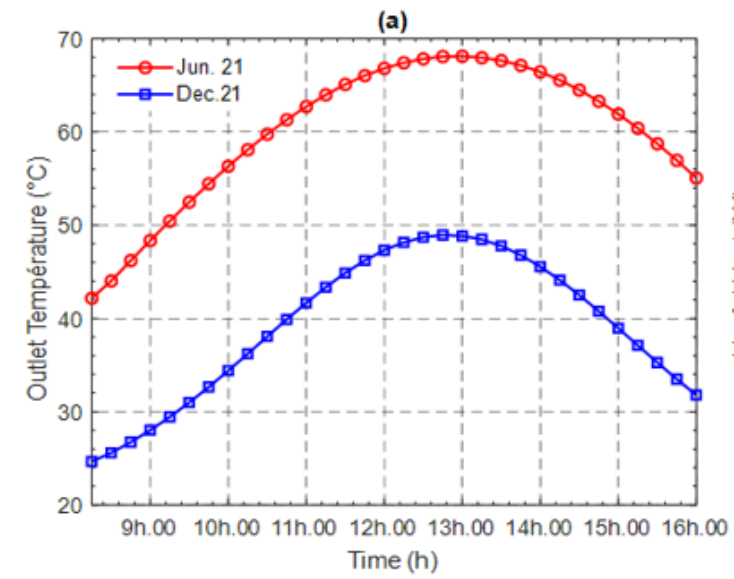

(b)

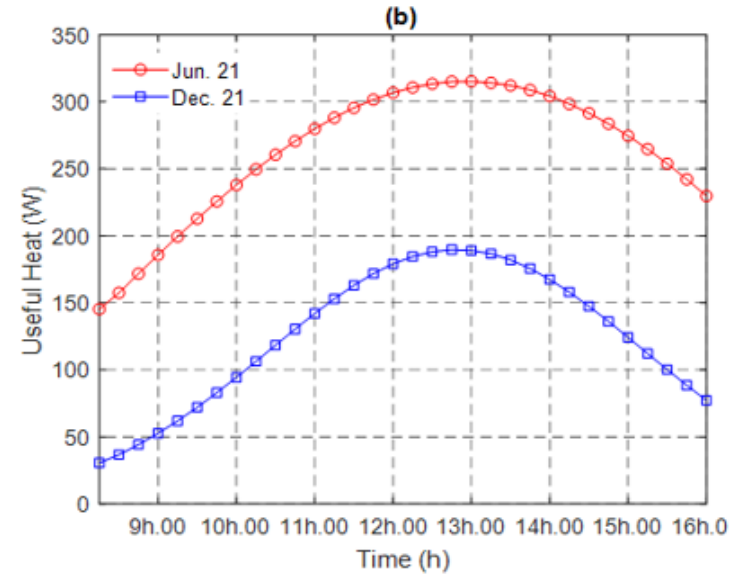

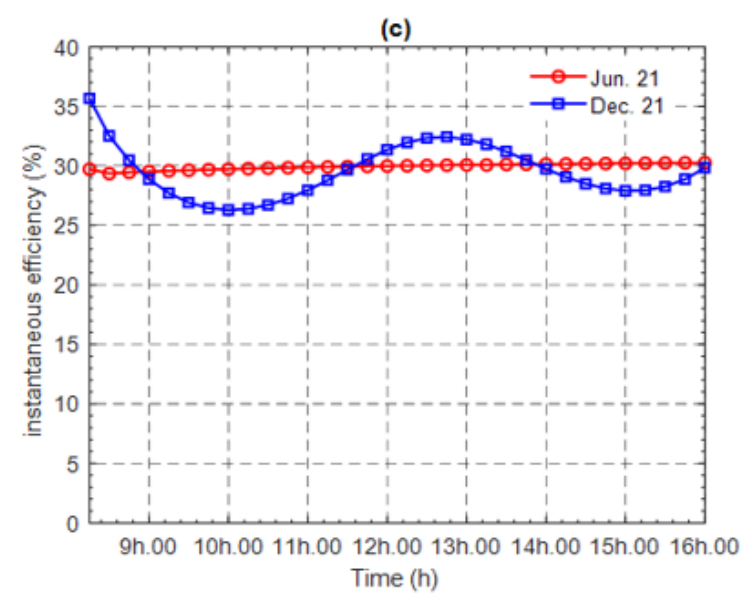

Fig. 4. Performance of the initial PTC configuration.

\subsection{Effect of the secondary reflector}

In the previous configuration, the solar rays reflected by the main reflector strike only part of the lateral surface of the collector tube. Lost rays can be recovered by installing a second reflector covering the rest of the surface of the tube. Thus, a uniform distribution of the flux around the surface and a better concentration of solar rays can be obtained. Figure 5 represents the efficiency variations for the two cases (December and June). The efficiency for the month of June is practically constant and is about $50 \%$, while the efficiency for the month of December fluctuates but its mean value is also about $50 \%$.Thus, the introduction of a second reflector makes it possible to increase the efficiency by $20 \%$.

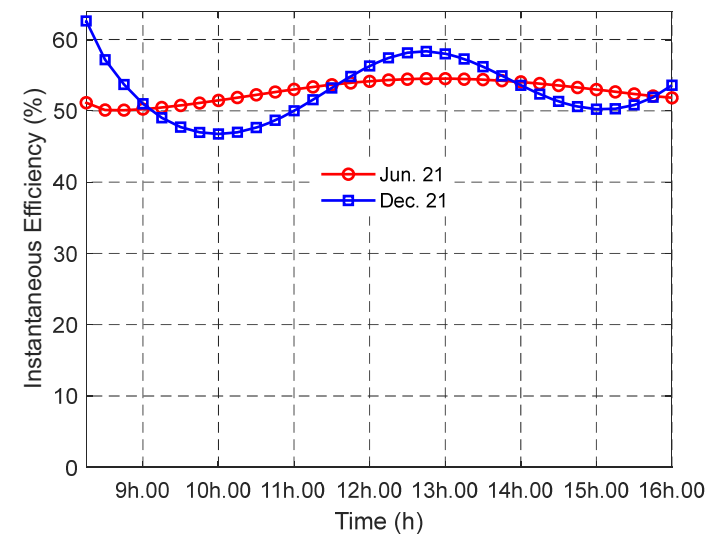

Fig. 4. Instantaneous efficiency versus time for a PTC with secondary reflector

\subsection{Effect of the tube length}

Figure 6 shows the variations of the average efficiency of the system as a function of the length of the tube for two cases: increasing the length without increasing the HTF mass flow rate; increasing both length and mass flow in a proportional manner. As can be seen, the average efficiency increases with length for 
the same mass flow rate of the fluid and can reach over $85 \%$. However, it must be taken into account in this situation that the length of the two reflectors also increases by the same proportion and likewise the cost of the installation. Increasing the mass flow rate of the fluid can offset the cost of the installation, which represents the second case. Nevertheless, the average efficiency in this case remains approximately constant around $50 \%$. Therefore, the choice depends on the application and the cost of the installation.

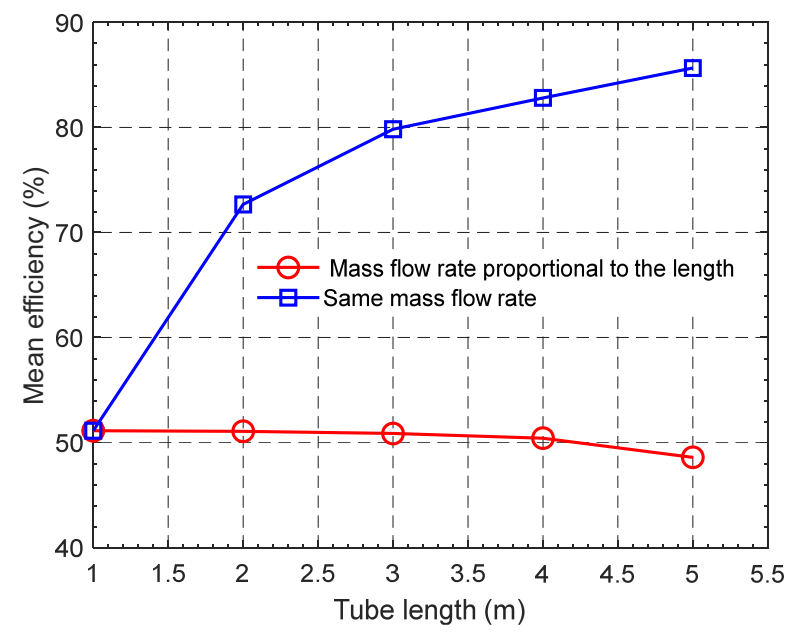

Fig. 6. PTC mean efficiency versus the collector tube length

\subsection{Effect of the collector tube thickness}

In this section, we consider the initial configuration (outside diameter equal to $10 \mathrm{~mm}$ ) with a second reflector. Figure 7 represents the average efficiency as a function of the flow rate of the fluid for different thicknesses of the tube. As can be seen, the efficiency decreases as the HTF mass flow rate increases for a given thickness of the tube. On the other hand, for a given mass flow rate of the HTF the efficiency increases by increasing the tube thickness. For example, an efficiency of about $75 \%$ can be reached with a mass flow rate of $0.001 \mathrm{~kg} / \mathrm{s}$ and a thickness of $4 \mathrm{~mm}$. However, based on our research on copper tube standards, most manufacturers offer tubes with a maximum thickness of around $3 \mathrm{~mm}$. Indeed, as the thickness of the tube increases, the tube weight and cost increase considerably. To get around this constraint, an energy storage material is used as a solution. This subject is one of our future perspectives.

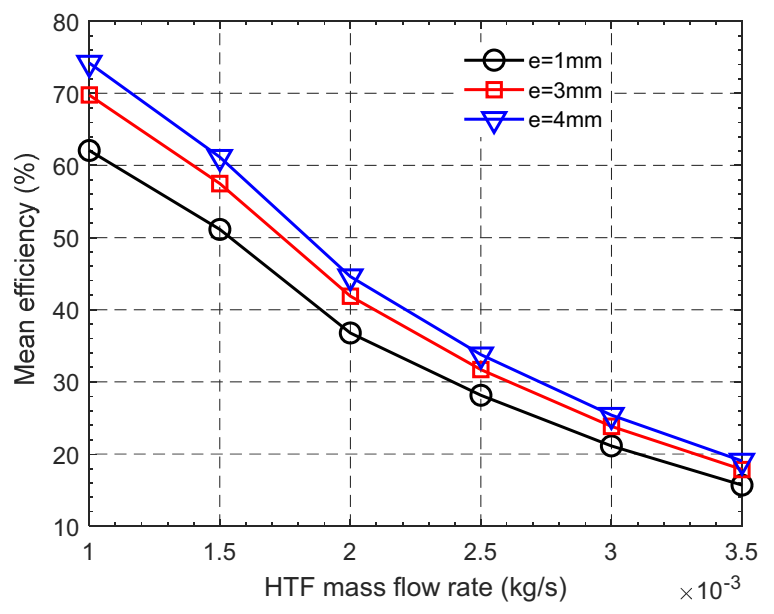

Fig. 7. PTC mean efficiency versus HTF mass flow rate and collector tube thickness.

\section{CONCLUSION}

The initial objective of this work is to find an optimal operation of a conventional PTC system. The procedure followed consists in considering a given configuration (dimensions, materials and HTF) with the data of the solar flux of the region considered (the city of Laghouat in our case). The optical analysis of the system consists of determining the distribution of solar flux around the collector tube. Then the thermal performance is determined by CFD analysis, which uses the output of the optical analysis as thermal boundary conditions.

The key parameters analyzed in this study are: the secondary reflector, length and thickness of the collector tube and the mass flow rate of the HTF. From the obtained simulation results, the following conclusions, regarding the optimal operation of a conventional PTC, can be drawn:

- For a given initial PTC configuration (dimensions and HTF properties), a secondary reflector can improve significantly the system performance. An increase in efficiency of about $20 \%$ can be obtained.

- Increasing the length of the receiver tube and the HTF mass flow rate in a proportional manner keeps the system efficiency approximately constant. For a given HTF mass flow rate, increasing the length of the collector tube increases significantly the efficiency of the system.

- For a given HTF mass flow rate, increasing the tube thickness increases the PTC efficiency. On the other hand, for a given thickness of the tube, increasing HTF mass flow rate decreases the PTC efficiency.

Further subjects can be investigated with particular focus on energy storage and realization of an optimization algorithm. 


\section{References}

1. J.C. R Kumar. J and M. A. Majid, Renewable energy for sustainable development in India: current status, future prospects, challenges, employment, and investment opportunities. Energy, Sustainability and Society $10: 2$ (2020)

2. I .Md Tasbirul, H. Nazmul, A.B Abdullah, and R.Saidur, A comprehensive review of state of the art concentrating solar power( CSP) thchnologies : current status and research trends. Renewable and sustainable energy reviews 91987-1018 (2018)

3. D.P. Tagle-Salazar, D.P.Krishna, Nigam, I.Carlos, and R.Solorio, Parabolic trough solar collectors: A general overview of technology, industrial applications, energy market, modeling, and standards, Gruyter (2020)

4. B. Roy, S. Shovan, R. D. Balmiki, Q. Das, K.P. Kataky, and A. Biswas, Parametric study of parabolic trough collector-A case study for the climatic conditions of Silchar, Assam, India, J. Sci. Technol. 12, 24-29 25F. 5 (2018)

5. A. Ghomrassi, H. Mhiri, and P. Bournot, Numerical study and optimization of parabolic trough collector receiver tube, J. Sol. Energy Eng. 137, 051003 (2015)

6. Y. Marif, H. Benmoussa, H. Bouguettaia, M. M. Belhadj, and M. Zerrouki, Numerical simulation of solar parabolic trough collector performance in the Algeria Saharan region, Energy Convers. Mange. 85, 521-529 (2014)

7. K. R. Kumar and K. S. Reddy, Effect of porous disc configuration on performance of solar parabolic trough concentrator, Heat Mass Transfer 48, 555571 (2012)

8. A. Mwesigye, T. Bello-Ochende, and J.P. Meyer, Heat transfer and thermodynamic performance of a parabolic trough receiver with centrally placed perforated plate inserts, Appl. Energy 136989 1003, (2014)

9. Y.-L. He, J. Xiao, Z.-D. Cheng, and Y.-B. Tao, A MCRT and FVM coupled simulation method for energy conversion process in parabolic trough solar collector, Renew Energy. 36 :976- 985, (2011)

10. E. Kaloudis, E. Papanicolaou, and V. Belessiotis, Numerical simulations of a parabolic trough solar collector with nanofluid using a two-phase model, Renew. Energy 97, 218-229 (2016)

11. Ansys Inc, ANSYS CFX-Solver Theory Guide, (2015)

12. Z.D. Cheng, Y.L. He, and F.Q. Cui, Numerical study of heat transfer enhancement by unilateral longitudinal vortex generators inside parabolic trough solar receivers, Int. J. Heat Mass Transf. 55, 5631-5641 (2012)

13. W. Fuqiang, T. Zhexiang, G. Xiangtao, T. Jianyu,H. Huaizhi, and L. Bingxi, Heat transfer performance enhancement and thermal strain restrain of tube receiver for parabolic trough solar collector by using asymmetric outward convex corrugated tube, Energy 114:275-292(2016).

14. E. Bellos, C. Tzivanidis, D. Tsimpoukis, Thermal enhancement of parabolic trough collector with internally finned absorbers, Sol. Energy $157: 514$ 531 (2017)

15. İ.H. Yilmaz and A. Mwesigye, Modeling, simulation and performance analysis of parabolic trough solar collectors: a comprehensive review, Appl. Energy 225 :135-174, (2018).

16. P. Benitez, J.C. Minano, R. Garcia, and R. Mohedano Arroyo, Contactless two-stage solar concentrators for tubular absorber, in: Opt. Sci. Eng. Instrum. 97, pp. 205-216 (1997)

17. D. Canavarro, J. Chaves, and M. Collares- Pereira, New second-stage concentrators (XX SMS) for parabolic primaries; Comparison with conventional parabolic trough concentrators, Sol. Energy 9298 105 (2013).

18. D. Rodriguez-Sanchez, G. Rosengarten, Improving the concentration ratio of parabolic troughs using a second-stage flat mirror, Appl. Energy 159 (2015) 620-632.

19. H.M. Regue, B.Bouali, T. Benchatti and A. Benchatti, Numerical Simulation of Conjugate Heat Transfer in a PTC with Secondary Reflector, International Journal of Heat and Technology, Vol. 38, No. 1, pp. 9-16 (2020)

20. G. Plancque, D. You, E. Blanchard, V. Mertens, C. Lamouroux, Role of chemistry in the phenomena occurring in nuclear power plants circuits, in Proceedings of the International Congress on Advances in Nuclear Power Plants, ICAPP, 2-5 May 2011, Nice, France (2011) 